ORIGINAL ARTICLE

\title{
Red cell or serum folate? Results from the National Pathology Alliance benchmarking review
}

\author{
M Galloway, L Rushworth
}

See end of article for authors' affiliations

.....................

Correspondence to: Dr. M J Galloway, City Hospitals Sunderland NHS Trust, Sunderland Royal Hospital, E Floor

Haematology Office, Kayll Road, Sunderland SR4 TTP, UK; mike.galloway@ chs.northy.nhs.uk

Accepted for publication 18 August 2003
Aims: The National Pathology Alliance benchmarking review has completed five years of data collection and analysis of the workload and organisation of haematology laboratories in the UK. This study analyses variation in practice in how laboratories respond to a request to determine whether or not a patient has folate deficiency.

Methods: A three year analysis of workload data on the number of serum/plasma folate and red cell folate assays performed on an annual basis for the period 1 April 1999 to 31 March 2002.

Results: Three diagnostic testing strategies were found, namely: serum/plasma folate only, red cell folate only, and both serum/plasma folate and red cell folate.

Conclusion: Evidence from the literature indicates that serum folate measurements provide equivalent information to red cell folate measurements when attempting to determine whether folate deficiency is present. There seems to be no basis for the routine testing of all samples for serum/plasma folate and a red cell folate.
T he National Pathology Alliance benchmarking review has now completed five annual cycles of data collection and analysis of the workload and organisation of haematology departments in the UK. ${ }^{1}$ When the benchmarking study was started there was no agreed national definition of what constituted a test and a request in haematology and blood transfusion. Therefore, a major part of the first two years' reports was to establish a national definition of tests and requests in haematology and blood transfusion, because without this no comparative assessment of a department's performance can be undertaken. In haematology, this has been achieved, with over $95 \%$ of departments now using the standard definition of tests and requests when completing the workload section of the questionnaire. Over the past two years, increasing attention has focused on the variation in diagnostic testing strategies used in different laboratories. This report analyses variation in practice in how laboratories respond to a clinical request to determine whether or not a patient has folate deficiency.

"We analysed the variation in practice of different diagnostic testing strategies that laboratories have established to determine whether or not a patient is deficient in folate"

Folate values can be measured using either a serum/plasma folate or a red cell folate assay. National guidelines indicate that a negative folate balance seen in hospital patients can result in a low serum folate value without folate deficiency. ${ }^{2}$ Therefore, low red cell folate, thought to indicate tissue deficiency, may be more important than a low serum folate in the diagnosis of folate deficiency. However, no references were given in these guidelines to substantiate this view.

Therefore, we analysed the variation in practice of different diagnostic testing strategies that laboratories have established to determine whether or not a patient is deficient in folate. We have also reviewed the literature to determine the appropriate diagnostic testing strategy in this situation.

\section{METHODS}

The method for data collection and analysis for the Pathology Alliance Benchmarking study has previously been described in detail. ${ }^{3}$ Briefly, each laboratory completes a data collection questionnaire with the number of tests that the laboratory performs on an annual basis. The haematology data collection proforma collects workload information on a range of 63 laboratory tests, together with data on laboratory activity in relation to the preparation and issue of blood components and blood products. A separate part of the questionnaire collects data on the staffing, organisation, costs, and quality outcomes for that service. For comparative purposes, laboratories are classified into one of five types of hospital-teaching hospitals, large, medium, or small district general hospitals, and paediatric hospitals. Teaching hospitals are those that include medical undergraduate and postgraduate teaching centres, in addition to receiving regular tertiary referrals in several pathology subspecialties. These hospitals would also have several regional subspecialties on site. Cluster A hospitals are large district general hospitals serving a population of over 320 000, which have an annual budget of over $£ 100$ million, and have several regional subspecialties on site. Cluster $\mathrm{C}$ hospitals are small district general hospitals serving a population of less than 225000 , which have an annual budget of less than $£ 60$ million. Cluster B hospitals are district general hospitals that fit in between cluster A and $\mathrm{C}$ hospitals. Other factors that are taken into account when allocating a hospital to a cluster are the number of beds in the hospital and whether the hospital is a cancer centre or a cancer unit. Each hospital is asked to confirm whether they have been allocated to the correct cluster group.

For the purpose of our study, the numbers of serum/plasma folate and red cell folate assays carried out each year in each laboratory for the period 1 April 1999 to 1 April 2002 were collected. Workload data were derived from both the haematology and biochemistry questionnaires to ensure that the total number of serum/plasma and red cell folates that were performed in each laboratory were collected.

A literature search was carried out to identify comparative studies of serum/plasma folate and red cell folate using 
Medline 1966 to February 2003 and EMBASE 1980 to February 2003.

\section{RESULTS}

Over the three year study period, approximately 80 National Health Service trusts each year submitted data on the number of red cell and serum/plasma folate tests that were undertaken in their department. As a result of trust mergers, the number of trusts entering data for 2001-2002 was reduced to 65 . Of these, 45 laboratories undertook serum and red cell folate assays. Figure 1 shows the data for these 45 trusts for the year 2001-2002. In one cluster B hospital the low volume of folate tests does not register on the chart. As can be seen from fig 1, there were three main diagnostic testing strategies used by laboratories. Nineteen laboratories relied primarily on serum folate only, with less than $10 \%$ of samples also being analysed for red cell folate. Twenty one laboratories relied primarily on the measurement of red cell folate, again with less than $10 \%$ of samples also being analysed for serum folate, and five laboratories tested most samples for both red cell and serum folates. The testing strategies that were in place did not seem to be related to the type of hospital. Further analysis of trends in diagnostic testing strategies showed there had been no change in clinical practice in the laboratories over the three years of the study period.

\section{DISCUSSION}

Our study showed a variation in practice in how laboratories respond to requests to determine whether or not a patient is deficient in folate. Our analysis of three years of data from the National Pathology Alliance benchmarking review shows that clinical practice has not changed over that time. Our study confirms the results of a previous smaller study that reported on an audit of the methodology used to measure folate concentrations in 24 laboratories in the South Thames region. ${ }^{5}$ In their study, $42 \%$ of laboratories relied on the serum folate assay only, $45 \%$ used the red cell folate only, and $12.5 \%$ used both assays. Does this variation in clinical practice matter? To answer this question, two aspects need to be considered. First, what evidence is there to support the various testing strategies, and second, what is the economic impact of the different strategies on costs?

The red cell folate assay has theoretical advantages. It has been suggested that red cell folate is a better indicator of tissue stores of folate and is therefore less susceptible to rapid changes in diet. ${ }^{2}$ However, when concentrations of liver folate have been measured, they have correlated equally well with serum folate and red cell folate measurements. ${ }^{6}$ In addition, there are disadvantages to performing the red cell folate assay. First, it is more complex to perform than the serum folate assay and requires more steps in sample handling before analysis, and this may be one of the reasons why the precision of the red cell folate assay is less than that of the serum folate assay. ${ }^{7}$ In addition, red cell folate concentrations are often low in a patients with B12 deficiency. ${ }^{2}$

We have not been able to identify comparative studies of red cell folate and serum folate using modern immunoassay methods as assessed against a reference standard such as a bone marrow. In an extensive clinical study, a significant correlation was found between red cell and plasma folate concentrations using a microbiological assay in a wide variety of clinical conditions in patients with megaloblastic and normoblastic bone marrows. ${ }^{8}$ Several studies have reported a good correlation between serum folate and red cell folate assays using immunochemistry analysers. Jaffe and Schilling reported a retrospective study that analysed the clinical usefulness of a low red cell folate when compared with serum folate. No reference standard was used in their study. From a total population of 1355 samples, 57 patients who had a low red cell folate were selected for further study. The results showed a significant correlation between serum and red cell folate $(r=0.55, \mathrm{p}<0.001)$. In only three of the 57 patients did the finding of a low red cell folate affect the clinical outcome; that is, these three patients had a low red cell folate, normal serum folate, and responded to oral folic acid. Their conclusion was that the measurement of red cell folate provided no additional clinical information over that provided by serum folate in $95 \%$ of their patients. ${ }^{9}$ Similarly, in an audit study Phekoo et al also reported a high degree of correlation between serum folate and red cell folate, particularly in patients with macrocytosis (mean cell volume above $100 \mathrm{fl}$ ). ${ }^{5}$ The conclusion from these studies is that in most patients a red cell folate provides no additional clinical information over a serum folate, particularly in patients who have macrocytosis. Thus, it seems that the measurement of serum folate would be the appropriate routine test to determine whether a patient has folic acid deficiency.

\section{"The benchmarking review will collect costing data on serum and red cell folate in next year's questionnaire"}

In theory, it should be possible to derive data on the value of the measurement of red cell folate assay compared with serum folate in the diagnosis of folate deficiency by analysing the data from the haematinics assay scheme that is part of the National Quality Assurance Scheme. ${ }^{7}$ However, in practice this is not possible. The samples for red cell folate

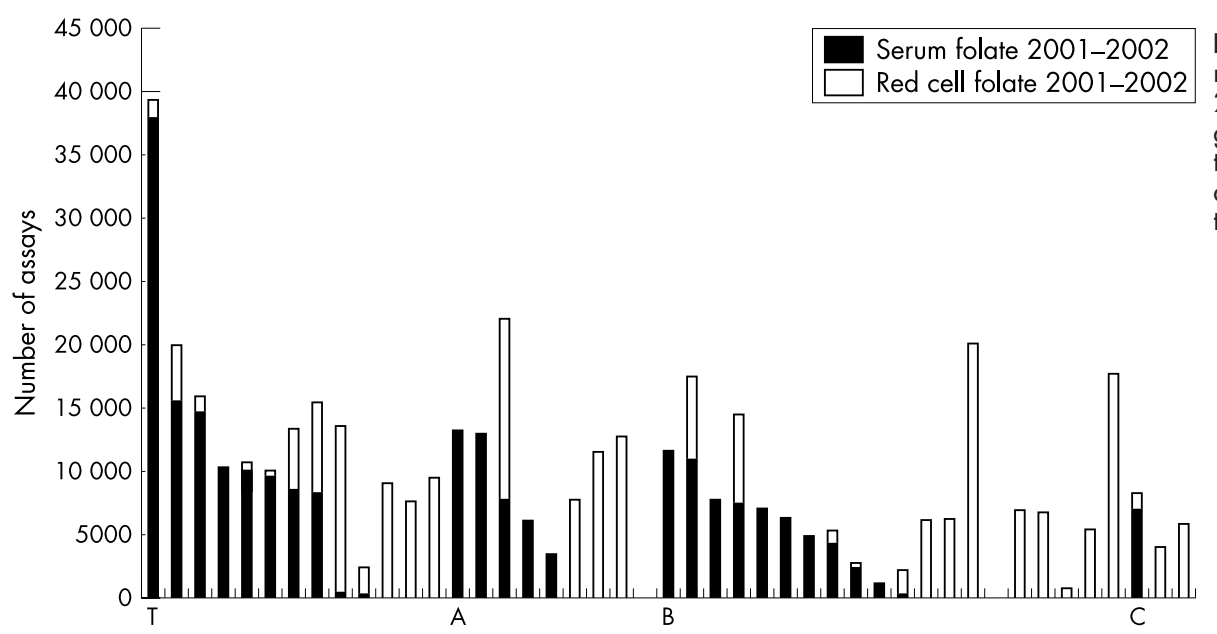

Figure 1 Number of serum folate and red cell folate assays performed for 2001-2002 by individual laboratories grouped by size of hospital: $\mathrm{T}$, teaching; A, large; B, medium; C, small district hospitals. Data reproduced with the permission of Newchurch Ltd. 
are prepared in anticoagulated whole blood and the samples for serum folate are prepared in a separate clotted sample. Therefore, because these are completely separate samples, no direct comparison is possible. As described below, to investigate this question a prospective comparative study is required with the use of a reference standard (MS Hamilton, personal communication, 2003).

As far as the economic consequences of the different testing strategies are concerned, costing data suggest that performing both red cell folate and serum folate assays doubles the cost of attempting to answer the question of whether or not a patient is folic acid deficient, whereas the cost of the serum and red cell folate assays are similar. ${ }^{2}$ However, no costing methodology was given in this report and in view of the increased staffing time required to process a red cell folate, higher costs for this test would be expected. To clarify this point, the benchmarking review will collect costing data on serum and red cell folate in next year's questionnaire.

One of the limiting aspects of a benchmarking study is that although questions regarding variation in clinical practice can be dealt with, this type of study cannot provide the evidence on which a diagnostic testing strategy can be based. This would require a prospective comparative study of red cell and serum folate compared with a reference standard, such as a bone marrow examination. Evidence in the literature indicates that serum folate should be the routine test that is used by laboratories to answer the question of whether a patient is folic acid deficient or not. However, the disadvantage of this approach is that in about $5 \%$ of patients the measurement of red cell folate may be useful in patients with macrocytosis who have a normal serum folate. The alternative strategy is to undertake red cell folate measurement, while recognising the disadvantages of increased staffing time to prepare the sample for analysis and a less precise assay when compared with serum folate. There seems to be no justification at present for the regular testing of all patient samples for both serum/plasma folate and red cell folate. To develop a diagnostic testing strategy in this area a further question to consider is what are the indications for requesting a folate measurement? A strategy to answer this question has been proposed by the American College of Physicians. ${ }^{10}$ This suggests that in patients with an mean cell volume greater than $110 \mathrm{fl}$ or in patients with a less raised mean cell volume who have other clinical features, such as cytopenias, peripheral neuropathy, unexplained cognitive dysfunction, or a condition known to mask a macrocytic response, then vitamin $\mathrm{B} 12$ and folate values should be measured. The routine test that should be used for this purpose is the serum/ plasma folate assay. In about $5 \%$ of cases where the serum folate concentration is normal, but there is still a high clinical suspicion that the patient has folate deficiency, then red cell folate should be measured.

The next step is to see whether this information can lead to a change in practice. The benchmarking process is an annual cycle of data collection, data analysis, production of the report, and feedback to participating laboratories. Therefore, we will present this information to the 2003 feedback meeting with participants and will monitor testing strategies

\section{Take home messages}

- Using data collected for the National Pathology Alliance benchmarking review, we identified three diagnostic testing strategies when determining whether a patient has folic acid deficiency-serum/plasma folate only, red cell folate only, and both serum/ plasma folate and red cell folate

- The serum folate assay provided equivalent information to the measurement of red cell folate and evidence from the literatures suggests that the serum folate assay should be the method of choice

- There seems to be no basis for the routine testing of all samples for serum/plasma folate and red cell folate, although in about $5 \%$ of cases where the serum folate concentration is normal, but there is still a high clinical suspicion of folate deficiency, red cell folate should also be measured

in subsequent years to determine whether there has been a change in practice.

\section{ACKNOWLEDGEMENTS}

We are grateful to Dr M S Hamilton, Director UK NEQAS haematinic assay scheme, for providing us with the details in relation to this scheme.

\section{Authors' affiliations}

M Galloway, L Rushworth, Clinical Management Unit, Centre for Health Planning and Management, Suite 2.0, Darwin Building, Keele University, Keele, Staffordshire ST5 5SP, UK

Both authors are members of the National Pathology Alliance benchmarking review haematology panel

\section{REFERENCES}

1 Pathology benchmarking report-haematology and blood transfusion 2000/ 2001. London: Newchurch, 2002.

2 British Committee for Standards in Haematology. Guidelines on the investigation and diagnosis of cobalamin and folate deficiency. Clin Lab Haematol 1994;16:101-15.

3 Dyson R, Atkinson H. Benchmarking laboratory performance. In: Galloway M, ed. Clinical director of pathology. Oxford: Radcliffe Medical Press, 1999:139-47.

4 Galloway M, Nadin L. Benchmarking and the laboratory. J Clin Pathol 2001;54:590-7.

5 Phekoo K, Williams Y, Schey SS, et al. Folate assays: serum or red cell? J R Coll Physicians Lond 1997;31:291-5.

6 Wu A, Chanarin I, Slavin G, et al. Folate deficiency in the alcoholic-its relationship to clinical and haematological abnormalities, liver disease and folate stores. Br J Haematol 1975;29:469-78

7 UK NEQAS. Haematinic assays scheme. Annual report 2001. Sutton Coldfield: UK NEQAS, 2002.

8 Magnus EM. Folate studies. Folate and vitamin B12 values in relation to bone marrow pattern. Scand J Haematol 1975;(suppl 24):1-111.

9 Jaffe JP, Schilling RF. Erythrocyte folate levels: a clinical study. Am J Haematol 1991;36:116-21.

10 Lancet JE, Rapoport AP. Macrocytosis. In: Black ER, Bordley DR, Tape TG, et al, eds. Diagnostic strategies for common medical problems. Philadelphia: American College of Physicians, 1999:585-95. 